\title{
An Insight to Burn Related Maternal Morbidity and Mortality in Pregnancy
}

\section{Rijal H, Rana A, Chalise G}

Department of Obstetrics and Gynecology, Tribhuvan University Teaching Hospital, Institute of Medicine, Kathmandu, Nepal.

Received: August 05, 2014; Accepted: January 10, 2015

\begin{abstract}
Aims: The aim of this study is to study morbidity and mortality of burn cases during pregnancy and postpartum period.
Methods: This is a retrospective study conducted at Tribhuvan University Teaching Hospital from April 1998 to July 2014. The data were retrieved from the records in burn ward, intensive care unit and emergency unit. Pregnant women with burn were studied for the nature, degree and the percentage of burn in relation to pregnancy outcome and mortality.

Results: There were 32 cases of burn patients with pregnancy. The most common source of burn was kerosene-induced flame (23) followed by domestic firewood (7), boiling water (1) and lightening (1). There were 25 cases of accidental burn and seven were suicidal burn. The age of the patients was $\leq 19$ years in 7, 20-24 in 13, 25-29 in 6 and 30-34 in 6 patients. Except for two cases of postpartum burn, all the others occurred during pregnancy between $6-40$ gestational week $\{<12$ weeks $=5,13-27$ weeks $=10,28-36$ weeks $=4,37-42$ weeks $=6$ and unknown $=7\}$. There was only one cesarean and three vaginal births and most resulting in stillbirth owing to higher percentage of burn above second degrees. The percentage of burn was $<30 \%$ in 13,30 $39 \%$ in $3,40-59 \%$ in $6,60-69 \%$ in 5 and $70-90 \%$ in 2 patients. There were nine mortality $(28.1 \%)$ in women above $30 \%$ burn.

Conclusions: The most common cause of burn in pregnancy was flame burn. Pregnant women need to be cautioned against flame burn and avoid using kerosene cooking stove to prevent themselves from burn, genuinely necessary steps to be propagated by all healthcare providers and also at the same time counseling against suicide to be done.
\end{abstract}

Keywords: maternal mortality; suicidal burn; wood fire burn.

\section{INTRODUCTION}

Maternal mortality is a priority research subject in Nepal. Upcoming studies have shown suicide as one of the few important contributes to the maternal mortality issues. ${ }^{1}$ Burning themselves to death has also been implicated as a suicidal motive. ${ }^{2}$ Significant female population in reproductive age group are being subjected to death due to burn in Nepal. ${ }^{3}$ While we commonly witness more incident within households, females are more prone as they are engrossed in domestic cooking using firewood. ${ }^{4}$ Burn acquired at domestic cooking using firewood in squatting position, a normal norm of rural lifestyle that results in extensive scarring in perineum, has been the cause of obstructed labor. ${ }^{5}$

This study values the role of multidisciplinary approach through a specialized team of anesthetist/ intensivist, physicians, plastic surgeons and obstetricians for management of these patients. This

\section{CORRESPONDENCE}

Dr Hima Rijal

Department of Obstetrics and Gynecology,

Tribhuvan University Teaching Hospital, Maharajgunj,

Kathmandu, Nepal

E-mail: rizhima@hotmail.com

Phone: +977-9841456576 study also helps to recognize, understand and educate us regarding current status of burns in pregnancy employing hospital-based data.

\section{METHODS}

This was a retrospective study conducted at Tribhuvan University Teaching Hospital between

15th April 1998 - July 2014 from burn ward, intensive care unit and emergency unit. Data source was the record book in burn ward, emergency, intensive care unit, and medical record section. Pregnant women with burn were studied to establish relationships between maternal age, nature of burn (homicidal, suicidal or accidental) including the degree and the percentage of total body surface (TBSA) area burn, source and intentionality of the burn and trimester of pregnancy at the time of the burn. Perinatal and maternal outcome were also studied. A fixed questionnaire was created and filled up. Informed consent was obtained from all the women. Approval from the Intitutional Review Committee of the hospital was also taken.

\section{RESULTS}

During last 16-years, 32 married women of reproductive age group were admitted with burn 
during pregnancy. Among them, thirty patients were pregnant and two were in puerperium. The intent of burn was accidental in 25 (78.1\%) and suicidal in $7(21.8 \%)$ patients (Table 1 ). Most of the suicidal burns were attempted by using kerosene and three of them succumbed to death. Among the accidental burn, 23 were flame burn, one due to hot water and one due to lightening.

\begin{tabular}{|lll|}
\hline \multicolumn{2}{|l|}{ Table 1 . Nature of burn, accidental/suicidal $(\mathrm{n}=32)}$. \\
\hline Cause of burn & Accidental & Suicidal \\
kerosene & 0 & 4 \\
Kerosene stove & 4 & 0 \\
Gas stove & 2 & 0 \\
Wood & 5 & 0 \\
Flame & 3 & 0 \\
Makal & 3 & 1 \\
Scald & 1 & 0 \\
lightening & 1 & 0 \\
Unspecified & 6 & 2 \\
\hline
\end{tabular}

Majority were second degree burn $(n=28,87 \%)$ and the deeper to dermis or third degree burn were four in number (13\%). Among the patients with third degree burn, two survived while two died, all four having had $60 \%$ burn. Burned out total body surface area (TBSA) ranged from 1 to $90 \%$. Higher percentage total body surface area affected by burn was noted to produce grave results in terms of maternal and fetal wellbeing. There was no mortality less than $30 \%$ burn $\{(n=10,(31.2 \%)\}$, more than $30 \% \quad(n=22,68.7 \%)$. Nine out of the twenty-two patients (40\%) with greater than $30 \%$ burn (Figure 1).

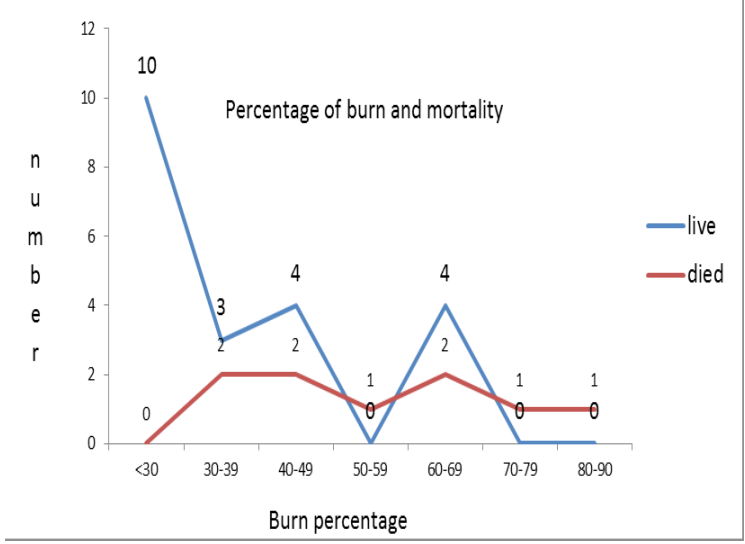

Figure 1. Burn and mortality ( $n=32)$.

Among the maternal death that occurred in 9/32 women who sustained burn injury, $3(9.3 \%)$ of them were suicidal and $6(18.7 \%)$ were accidental. The age of the women ranged from 18-34 years and the pregnancy varied from 16-40 weeks. Five of the pregnancy being above 30 weeks period of gestation and two of them being 40 weeks with the record of one fresh stillbirth.

The maternal complications that led to mortality were shock, respiratory distress and sepsis with one sustaining corneal abrasions/perforation. The seriousness of the condition indicated by death within one day in three cases and three days in another, while women were kept alive up to 53 days in one case (Table 2).

\begin{tabular}{|c|c|c|c|c|}
\hline $\begin{array}{l}\text { Age } \\
\text { (years) }\end{array}$ & $\begin{array}{l}\text { Gestational } \\
\text { age } \\
\text { (weeks) }\end{array}$ & $\begin{array}{l}\text { Burn } \\
\%\end{array}$ & $\begin{array}{l}\text { Type/cause } \\
\text { of burn }\end{array}$ & $\begin{array}{l}\text { Burn to } \\
\text { mortality } \\
\text { interval } \\
\text { (days) }\end{array}$ \\
\hline 18 & 35 & 75 & $\begin{array}{l}\text { Accidental } \\
\text { (Kerosene stove) }\end{array}$ & 1 \\
\hline 26 & 16 & 55 & $\begin{array}{l}\text { Suicidal } \\
\text { (kerosene) }\end{array}$ & 29 \\
\hline 18 & $*$ & 60 & $\begin{array}{l}\text { Accidental } \\
\text { (Kerosene stove) }\end{array}$ & 53 \\
\hline 31 & 40 & 37 & $\begin{array}{l}\text { Accidental } \\
\text { (woodfire) }\end{array}$ & 31 \\
\hline 20 & 27 & $30-35$ & $\begin{array}{l}\text { Suicidal } \\
\text { (kerosene) }\end{array}$ & 17 \\
\hline 19 & 40 & 60 & $\begin{array}{l}\text { Accidental } \\
\text { (flame burn) }\end{array}$ & 36 \\
\hline 20 & * & 40 & Suicidal & 1 \\
\hline 18 & 30 & 90 & Accidental & 3 \\
\hline 20 & 36 & 40 & Accidental & 1 \\
\hline
\end{tabular}

Note : * Gestational age not known

The pregnancy ranged from G1-G6. Age of the patients ranged from 18-34 years, less than $19(\mathrm{n}=7$, $22 \%) ; 20-24(n=13,40.6 \%) ; 25-29(n=6,18.7 \%)$ and $30-34(n=6,18.7 \%)$. with the mean age of the burn affected pregnant women being 23.4 years (Figure 2 ).

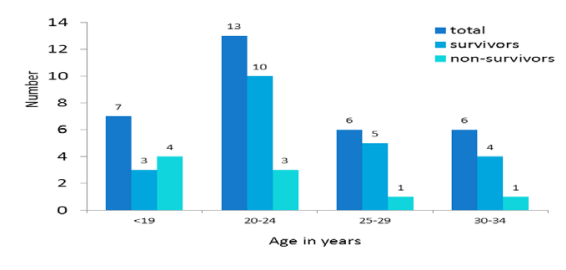

Figure 2. Age in years $(n=32)$.

Two postpartum cases, one who caught fire on saree end while lactating. Period of gestation was less than 12 weeks $(n=5,15.6 \%) ; 13-27$ weeks $(n=10,31.2 \%)$; 28-36 weeks $(n=4,12.5 \%)$ and $37-42$ weeks $(n=6$, 
18.7\%) with dates not verified in five cases (Figure $3)$.

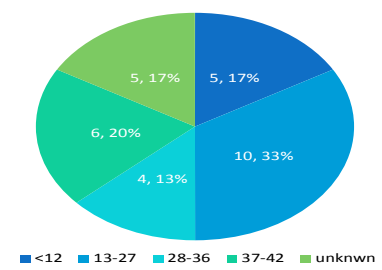

Figure 3. Period of gestation in weeks $(n=32)$.

Labor was induced but failed to progress in one and needed cesarean section. Hospitalization period was 1-66 days (mean $=26$ days). Hospitalizations in for those who expired were 1- 51days

(mean $=19$ days) and who survived were 2-66 days (mean $=33$ days) (Figure 4$)$.

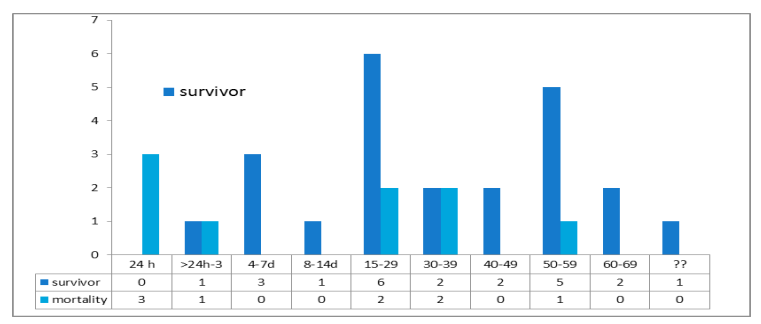

Figure 4. Length of hospitalization $(n=32)$.

\section{DISCUSSION}

This retrospective study showed that burn injury during pregnancy is seldom met in our hospital.

Review of hospital records revealed that hardly two cases of burn in pregnancy are admitted per annum with four thousands deliveries and about 250 mixed pregnancies ending uneventfully. And this finding is similar to the other studies reporting incidence of small number of cases of burn in pregnancy. ${ }^{6-9}$ Burn injuries during pregnancy have adverse effects on maternal and fetal outcome with high incidence of IUD, abortion and premature labor. Pregnancy itself does not alter the maternal survival. ${ }^{10}$

The possibility of pregnancy must be considered when any woman of reproductive age sustains a burn injury. Although rare, an extensive burn during pregnancy is a serious complication. In the study done by Agrawal et $\mathrm{al}^{11}$ reported $12.29 \%$ of all women of reproductive age admitted with burns were pregnant. Because pregnancy tests were not done routinely the true incidence of pregnancy associated with burn injuries, especially in the first trimester, remains unknown.
Burn can happen accidentally during pregnancy, fetal wellbeing need special attention.

There are specific physiological changes that occur during pregnancy that may have an impact after thermal injury on maternal and fetal well-being. Burns causes many maternal physiological changes and places additional stress on systems that are already highly modified. Pregnancy is associated with hyperdynamic cardiovascular state. After burns there is increased capillary permeability and third space loss leading to hypovolemia, which may in turn lead to hypotension if the patient is inadequately resuscitated leads to placental insufficiency, fetal ischemia, hypoxia and acidosis leading to premature birth. Thus aggressive fluid resuscitation, upright posture and oxygen supplementation should be provided to the mothers even in the absence of smoke inhalation. ${ }^{12,13}$ And fetus in utero calls for extra caution. ${ }^{14-16}$

In this study women of reproductive age group have got burn injuries mostly while doing household tasks. Although most of them were accidental, some were intentional and maternal mortality was more in intentional burns. Most of the maternal mortality (40\%) had TSAB above 30\%. Kamini et $\mathrm{al}^{9}$ also showed in their study that the maternal and fetal mortality rates were higher when the burn was suicidal. Higher degree of burn is directly proportionate to severity of outcome.All third degree burn $(n=4)$ resulted in poor outcomes in our study. Prevention of hypovolemic shock by adequate early fluid therapy is required to maintain the uterine blood flow, which in turn maintains fetal tissue pO2 levels within the normal range. It is recommended to maintain the mother's blood pressure within the normal range and a urine output of 30-60 $\mathrm{ml} / \mathrm{h}$. Ventilatory support should be initiated when maternal pO2 is less than $60 \mathrm{~mm} \mathrm{Hg}$ as inhaled carbon monoxide can cross the placental barrier to compete for binding sites on fetal hemoglobin, provoking fetal cardiac edema, and affecting cardiac development. ${ }^{17}$

There have been concerns of perineal burns posing a difficulty for vaginal birth or cesarean delivery with respect to abdominal burn injuries imparting situational challenges. This runs everywhere even in the best of the hospital, equipped with burn care facilities or having guiding protocol for the management. ${ }^{18,19}$ Women in developing countries typically squat around cooking fires and perineal 
burns result in scarring of genitalia leading to obstructed labour and abdominal burn scar may sometimes interfere in abdominal incision while performing cesarean sections. However, in our study spontaneous labor occurred in most cases, while induction was done in one case and resulted in fresh stillbirth.

Our study showed comparable figures of the nature and type of burn, most common being accidental flame burn. This study also showed the maternal mortality comparable to the figures mentioned in most literature as $39 \%-68.6 \% .^{7,9,13,20}$ Despite of sustaining large body surface destruction by burn and long period of hospitalization many patients were successfully sent home after wound management with skin graft.

\section{CONCLUSIONS}

Pregnancy does not influence maternal outcome after thermal injury and best chance for fetal survival is to ensure maternal survival. Pregnant women need to be cautioned against flame burn and avoid using kerosene-cooking stove to prevent them from burn. Maternal survival is less likely if the burn wound exceeds $30 \%$ total body surface area. Thermal injury does increase the risk of spontaneous abortion and premature labour and foetal survival depends upon foetal maturity. Urine pregnancy test should be done to all women in reproductive age group admitted in burn ward.

\section{ACKNOWLEDGEMENT}

I would like thank Prof Ishwor Lohani and his team, and all the staffs of burn ward, intensive care unit, and emergency department $\mathrm{T}$ U Teaching Hospital for providing data of burn pregnant cases.

\section{DISCLOSURE}

The authors report no conflicts of interest in this work. No violation of human rights and safety.

Funding: Nil

\section{REFERENCES}

1. Pyakurel R, Sharma N, Paudel D, Coghill A, Sinden L, Bost $\mathrm{L}$, et al. Cause of death in women of reproductive age in rura Nepal obtained through community-based surveillance: is reducing maternal mortality the right priority for women's health programs? Health Care Women Int 2014;1:1-8

2. Gupta BD, Gambhir SO. A unique trend of murder-suicide in the Jamnagar region of Gujarat, India: a retrospective study of 5 years. J Forensic Leg Med 2008;15(4):250-5.

3. Saleh S, Gadalla S, Fortney JA, Rogers SM, Potts DM. Accidental burn deaths to Egyptian women of reproductive age. Burns Incl Therm Inj 1986;12(4):241-5.

4. Liu EH, Khatri B, Shakya YM, Richard BM. A 3 year prospective audit of burns patients treated at the Western Regional Hospital of Nepal. Burns 1998;24(2):129-33.

5. Pant R, Manandhar V, Wittgenstein F, Fortney JA. Genital burns and vaginal delivery. Internet $\mathrm{J}$ Gynecol Obstet 1995;50(1):61-3

6. Subrahmanyam M. Burns during pregnancy: effect on maternal and fetal outcomes. Ann Burns Fire Disasters 2006;19(4):177-9.

7. Fildes J, Reed L, Jones N, Martin M, Barrett J. Trauma: the leading cause of maternal death. J Trauma. 1992;32(5):643-5.

8. Maghsoudi H, Samnia R, Garadaghi A, Kianvar H. Burns in pregnancy. Burns 2006 ;32(2):246-50.

9. Karimi H, Momeni M, Rahbar H. Burn injuries during pregnancy in Iran. Int J Gynaecol Obstet 2009;104(2):132-4.
10. Akhtar MA, Mulawkar PM, Kulkar HR. Burn in pregnancy effects on maternal and fetal outcome. Burns 1994;20(4):3515 .

11. Agrawal P. Thermal injury in pregnancy: predicting materna and fetal outcome. Indian J Plast Surg $2005 ; 38(2)$ : 95-9.

12. Taylor JW, Plunkett GD, Manus WF, Pruitt BA. Thermal injury during pregnancy. Obstet Gynecol. 1976;47:434-8.

13. Bartle EJ, Sun JH, Wang XW. Burns in pregnancy. J Burn Care Rehabil 1988;9:485-7.

14. Mokube JA, Verla VS, Mbome VN, Bitang AT. Burns in pregnancy: a case report from Buea Regional Hospital, Cameroon. Pan Afr Med J.2009;3:21

15. Charles G, Marhic C, Guilbaud J, Carsin H, Ponties JE, Perrot $\mathrm{J}$, et al. Burns and pregnancy: a case of severe burn occurring at the beginning of pregnancy, maternal and fetal survival. J Gynecol 1989;18(4):501-5.

16. Guo SS, Greenspoon JS, Kahn A. Management of burn injuries during pregnancy. Burns 2001;27(4):394-7.

17. Matthews RN. Obstetric implications of burns in pregnancy. Br J Obstet Gynaecol 1982; 89:603-9.

18. Kumar PE. Exploiting potency of negative pressure in wound dressing using limited access dressing and suction-assisted dressing.Indian J Plast Surg. 2012;45(2):302-15.

19. 19. Rustogi R, Mill J, Fraser JF, Kimble RM. The use of anticoat in neonatal burns. Burns 2005;31(7):878-82.

20. Rana A, Pradhan N , Manandhar B, Bitsta KD, Adhikari S, Gurung G. Maternal mortality over the last decade: a changing pattern of death due to alarming rise in hepatitis in the latter five-year period. Int J Gynaecol Obstet 2009;104(2):132-4. 